\title{
The new UK internal medicine curriculum
}

\author{
Author: David Black ${ }^{\mathrm{A}}$
}

\section{Reform of physician education is needed to meet the needs of patients, based on comorbidities, chronic disease management and complexity. The Joint Royal Colleges of Physicians Training Board has developed a new internal medicine curriculum for physician training that aims to not only deliver this expectation, but will simplify competency- based education, smooth the transition to the medical registrar role and hopefully fill some of the current empty funded training posts. However, the change process is complex and requires close working with the General Medical Council and other partners in curriculum delivery.}

KEYWORDS: Core medical training, curriculum, general internal medicine, training

The new UK-wide internal medicine curriculum, designed to replace both core medical training and general internal medicine, is currently hoped to start in late 2018 but more likely 2019. It represents a significant refocusing of training to meet the patient needs that were clearly espoused in both the Royal College of Physicians' Future Hospital Commission report and the Shape of Training review. ${ }^{1,2}$

The new curriculum has been planned to help all physicians become expert general medical registrars before specialisation and will have a particular focus on formally demonstrating the General Medical Council's (GMC) requirements around generic professional capabilities. It does not shorten training.

A particular aim of the new internal medicine curriculum is to ensure that all physicians are better equipped to cope with the complex needs of patients, including multiple pathology and chronic disease management. In the early years of training, there will be a greater focus on simulation for procedures and human factors as well as outpatient experience. All trainees should get experience in the expert care of older people and the intensive care unit/high dependency unit. However, the key attribute remains that all will have the capacity to care for acutely unwell patients within their scope of practice.

We are also taking the opportunity to very significantly simplify competency-based education and move away from the greatly criticised 'tick-box approach' to current curriculum delivery, especially in core medical training. Instead of 120

Author: ${ }^{A}$ medical director, Joint Royal Colleges of Physicians Training Board, London, UK competencies in core medical training alone, the new internal medicine curriculum has 13 'competencies in practice', which must be delivered over the usual indicative 7 years of training. ${ }^{3}$ This new approach to training aims to focus on the outcomes of training and to define that in terms of the work that a trainee is trusted to do. By the end of training, doctors are trusted to undertake all work tasks independently without supervision. These tasks are known as entrustable professional activities (EPAs) or competencies in practice (CiPs). A CiP is defined as a 'critical path to professional work that can be identified as a unit to be entrusted to a trainee once efficient competency has been reached'. ${ }^{45}$ CiPs emphasise the role of observation and judgement as it occurs in real life. For example, a consultant already decides what each trainee can be trusted to do as well as determining the amount of supervision they need to undertake an activity safely. These judgements are made routinely in the workplace and by the end of training a doctor must be trusted to undertake all key work tasks needed to work as a consultant and that becomes the outcome and endpoint of training.

The model set out in Fig 1 should ensure many more trainees complete 3 years of internal medicine and help fill the current rota gaps ('stage 1' of internal medicine). This will include a supported transition into a medical registrar year during the third year of internal medicine. There will then be competitive selection into higher specialty training. The internal medicine CiPs will be embedded through all physician training programmes, indeed it is likely that the GMC will make a number of these generic across all postgraduate specialty programmes. There will then be two broad groups of physicians completing the training programme. ${ }^{3}$ The vast majority, who will be making a significant contribution during training to unscheduled care in various ways, should come out at the end certified as both an 'ologist' and in internal medicine. A much smaller group of specialties, all of which have minimal contribution to unscheduled care, will continue single 'ologies'; they will still have to demonstrate many of the generic internal medicine CiPs during their training. The latter small group of specialties often already have many different entry routes, not just core medical training, and so will still include selecting some higher specialty trainees in the future just after 2 years of internal medicine.

The consultation has been considerable. In the summer of 2015, all 9,500 current physician trainees were contacted by the three college trainees committees (London, Edinburgh and Glasgow) to get input. Multiple meetings have been held with all specialty advisory committees and heads of school, councils of all three colleges, together with regional advisors 

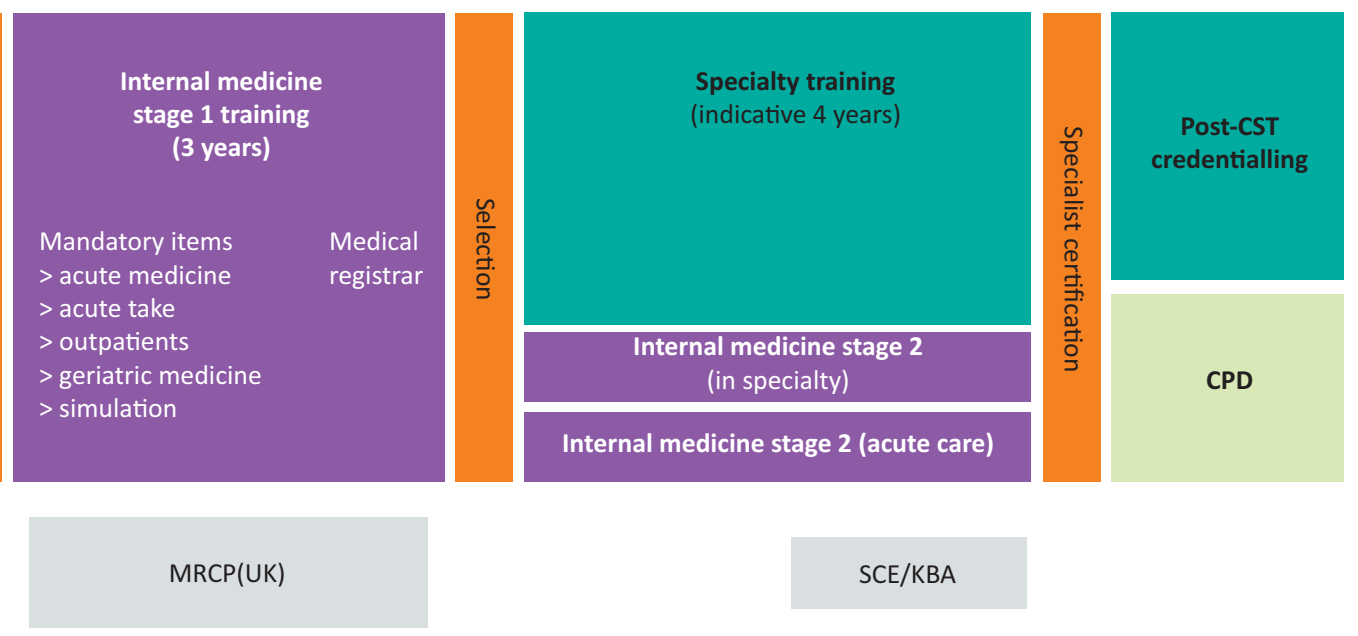

Workplace-based assessment

Fig 1. Proposed outline model for physician training. Reproduced with permission from the Joint Royal Colleges of Physicians Training Board. $\mathrm{CPD}=$ continuing professional development; $\mathrm{CST}=$ Completion of Specialty Training; $\mathrm{KBA}=$ knowledge-based assessment; $\mathrm{MRCP}(\mathrm{UK})=\mathrm{full}$ membership of the Royal College of Physicians; $\mathrm{SCE}=$ specialty certificate examinations.

and postgraduate deans. Importantly, there has been lay input and input from the service, particularly from NHS England. One important driver has been the workforce modelling that suggests this could lead to a considerable number of the current gaps at medical registrar level being filled and the opportunity to bring some more 'trust grade jobs' into formal training.

Road blocks remain. It is not yet clear whether the term 'internal medicine' is actually allowed legally! The GMC are on the case. The GMC has also been consulting about the structure of new outcome-based curricula ${ }^{6}$ and until that has been completed, we cannot finally write the new curriculum and get it approved. It is hoped to get approval in the summer or autumn of 2017 to allow deaneries and Health Education England local offices to carefully plan programme implementation. Also, there is a major job to be done in each deanery/Health Education England local office in reorganising posts and programmes and working on the transitional arrangements for 2020-2022. No change is simple, but there is huge determination to make this work. The intensive scrutiny of the proposals, confirm that many consultants, educators and trainees believe that this is a significant step forward, not only to meet patient needs, but to retain the high quality of physician specialist practice in the UK while addressing some of the real challenges around transition to the medical registrar role and rota gaps. We are totally committed to getting this to work first time; the Joint Royal College of Physicians Training Board is not looking for any sort of 'big bang', but instead to gradually introduce this new programme, year on year, starting in 2018 (or more likely 2019). We also want to make it as easy as possible for any current trainees taking time out by guaranteeing them a return with an internal medicine year 3 whenever they wish to return.
During the development of this programme, we heard repeatedly that wherever one ends up as a physician, and however specialised, the broadest most detailed grounding in internal medicine was the most important underpinning for future successful practice. Within the financial constraints of training, we hope that this will prove a significant step forward.

\section{References}

1 Future Hospital Commission. Future hospital: caring for medical patients. A report from the Future Hospital Commission to the Royal College of Physicians. London: RCP, 2013.

2 Greenaway D. Securing the future of excellent patient care. London: Shape of Training, 2013.

3 Joint Royal Colleges of Physicians Training Board. Development of the new internal medicine curriculum. London: JRCPTB, 2016. www.jrcptb. org.uk/new-internal-medicine-curriculum [Accessed 13 January 2017].

4 Ten Cate O, Chen HC, Hoff RG et al. Curriculum development for the workplace using Entrustable Professional Activities (EPAs): AMEE Guide No. 99. Med Teach 2015;37:983-1002.

5 Ten Cate O. Entrustability of Professional Activities and competencybased training. Med Educ 2005;39:1176-7.

6 General Medical Council. Standards from curricula and assessment review. London: GMC, 2016. www.gmc-uk.org/education/29569.asp [Accessed 13 January 2017].

Address for correspondence: Professor David Black, Joint Royal Colleges of Physicians Training Board, St Andrews Place, Regent's Park, London NW1 4LE, UK.

Email: David.Black@jrcptb.org.uk 